Cochrane Database of Systematic Reviews

\title{
Support for mothers, fathers and families after perinatal death
} (Review)

Koopmans L, Wilson T, Cacciatore J, Flenady V

Koopmans L, Wilson T, Cacciatore J, Flenady V.

Support for mothers, fathers and families after perinatal death.

Cochrane Database of Systematic Reviews 2013, Issue 6. Art. No.: CD000452.

DOI: 10.1002/14651858.CD000452.pub3.

www.cochranelibrary.com 
HEADER 1

ABSTRACT

PLAIN LANGUAGE SUMMARY

BACKGROUND

OBJECTIVES

METHODS

RESULTS

DISCUSSION

AUTHORS' CONCLUSIONS

ACKNOWLEDGEMENTS

REFERENCES

CHARACTERISTICS OF STUDIES

APPENDICES

FEEDBACK

WHAT'S NEW

HISTORY

CONTRIBUTIONS OF AUTHORS

DECLARATIONS OF INTEREST

SOURCES OF SUPPORT

INDEX TERMS

\section{TABLE OF CONTENTS}


[Intervention Review]

\title{
Support for mothers, fathers and families after perinatal death
}

\author{
Laura Koopmans $^{1}$, Trish Wilson ${ }^{2}$, Joanne Cacciatore ${ }^{3}$, Vicki Flenady 4 \\ 1Mater Medical Research Institute, Mater Health Services, Woolloongabba, Australia. 2Education and Support Services, Mater Mothers' \\ Hospital, South Brisbane, Australia. ${ }^{3}$ School of Social Work, Arizona State University, Phoenix, Arizona, USA. ${ }^{4}$ Translating Research Into \\ Practice (TRIP) Centre - Mater Medical Research Institute, Mater Health Services, Woolloongabba, Australia
}

Contact address: Laura Koopmans, Mater Medical Research Institute, Mater Health Services, Level 2 Quarters Building, Annerley Road, Woolloongabba, Queensland, 4102, Australia. lauskoopmans@hotmail.com, laura.koopmans@mater.org.au.

Editorial group: Cochrane Pregnancy and Childbirth Group.

Publication status and date: New search for studies and content updated (no change to conclusions), published in Issue 6, 2013.

Citation: Koopmans L, Wilson T, Cacciatore J, Flenady V. Support for mothers, fathers and families after perinatal death. Cochrane Database of Systematic Reviews 2013, Issue 6. Art. No.: CD000452. DOI: 10.1002/14651858.CD000452.pub3.

Copyright @ 2013 The Cochrane Collaboration. Published by John Wiley \& Sons, Ltd.

\section{A B S T R A C T}

\section{Background}

Provision of an empathetic, sensitive, caring environment and strategies to support mothers, fathers and their families experiencing perinatal death are now an accepted part of maternity services in many countries. Interventions such as psychological support or counselling, or both, have been suggested to improve outcomes for parents and families after perinatal death.

\section{Objectives}

To assess the effect of any form of intervention (i.e. medical, nursing, midwifery, social work, psychology, counselling or community-based) on parents and families who experience perinatal death.

\section{Search methods}

We searched the Cochrane Pregnancy and Childbirth Group's Trials Register (28 January 2013) and article bibliographies.

\section{Selection criteria}

Randomised trials of any form of support aimed at encouraging acceptance of loss, bereavement counselling, or specialised psychotherapy or counselling for mothers, fathers and families experiencing perinatal death.

\section{Data collection and analysis}

Two review authors independently assessed eligibility of trials.

\section{Main results}

No trials were included.

\section{Authors' conclusions}

Primary healthcare interventions and a strong family and social support network are invaluable to parents and families around the time a baby dies. However, due to the lack of high-quality randomised trials conducted in this area, the true benefits of currently existing interventions aimed at providing support for mothers, fathers and families experiencing perinatal death is unclear. Further, the currently available evidence around the potential detrimental effects of some interventions (e.g. seeing and holding a deceased baby) remains inconclusive at this point in time. However, some well-designed descriptive studies have shown that, under the right circumstances and guided by compassionate, sensitive, experienced staff, parents' experiences of seeing and holding their deceased baby is often very positive. The sensitive nature of this topic and small sample sizes, make it difficult to develop rigorous clinical trials. Hence, other research 
designs may further inform practice in this area. Where justified, methodologically rigorous trials are needed. However, methodologically rigorous trials should be considered comparing different approaches to support.

\section{PLAIN LANGUAGE SUMMARY}

\section{Support for mothers, fathers and families after perinatal death}

It is devastating for parents and families when a baby dies. It is estimated that approximately one in five parents will suffer from intense and prolonged grief following the death of a baby around the time of birth. It is essential that parents and families are offered, and have access to, appropriate support from caregivers and their direct social network. Yet, little is known about the role and the true effectiveness of different types of bereavement support for parents and their families. This review aimed to identify clinical trials to assess the effect of different types of bereavement support interventions and/or counselling for parents experiencing perinatal death. There are no included studies on this topic. For the update of this review we identified one new trial, which is currently awaiting classification. More research in this area is needed. 


\section{B A C K G R O U N D}

The death of a child around the time of birth is one of the most profound, stressful events an adult may experience (Bonanno 2001; Fish 1986; Wing 2001). For decades, mothers (and fathers) were separated from their stillborn or dying babies in the belief that grief could be prevented if no attachments were formed. After it was established that attachment relationships between mother and child are already formed during pregnancy, (Giles 1970; Kennell 1970), research has focused on exploring the substantial impact of perinatal death on parents and families.

\section{Grief reactions}

Normal parental grief reactions immediately following perinatal death have been well documented and resemble those in other bereavement situations (e.g. after the death of a spouse). Profound sadness, depressed mood, irritability, preoccupation, anxiety and changes in eating and in sleeping patterns are all considered to be part of a normal grief response (Burnett 1997; Parkes 1972; Raphael 1984). Symptoms of acute grief typically subside with time and for most people the intensity has significantly reduced by six to 12 months post-loss (Bonanno 2001; Shear 2011). Yet, grief recovery or rather 'the normalisation of the psychosocial effects of perinatal death' has been reported to take as long as five to 18 years (Gravensteen 2012).

Pathological responses to bereavement include bereavementrelated major depression, post-traumatic stress disorder (PTSD) and complicated grief (Lichtenthal 2004; Stroebe 2008a) and it is not uncommon that these conditions co-occur in bereaved individuals (Shear 2005). Pathalogical grief responses are more likely to occur in patients with a pre-existing mental health diagnosis. Although the majority of bereaved parents will experience normal grief, bereaved parents have been repeatedly identified to be at increased risk of complicated grief (Badenhorst 2007; Hughes 2003; Korenromp 2007; Radestad 2009). Persisting and significant grief-related problems may be more prevalent in a subset of parents. Kersting et al (2007) found that recently bereaved mothers who had a termination of pregnancy (TOP) for fetal abnormalities, were significantly more likely than controls to suffer from a range of psychiatric disorders for up to 14 months after their loss (Kersting 2007). In this cohort, acute stress disorders such as PTSD, were mostly resolved at 14 months post-loss, while anxiety and affective disorders were the most common diagnoses at the 14month point.

Post-traumatic stress has also been reported in the subsequent pregnancy following perinatal death. Although a clinical diagnosis of PTSD was not made, one study (Turton 2001) reported that $20 \%$ of women fulfilled the criteria of PTSD during a pregnancy following stillbirth, compared with the general PTSD population incidence of $5 \%$ to $10 \%$ (Keane 2009). One year postpartum, however (i.e. following the birth of a healthy baby), both current and lifetime PTSD rates in these women had decreased to around 5\%, similar to population levels. At seven-year follow-up, there were no longer significant differences in PTSD and major depression between bereaved mothers and controls.

\section{Relationships}

Perinatal death has been identified as a risk factor for relationship break-down (Najman 1993; Vance 2002). Gold and colleagues found that stillbirth increased the risk of parental separation by $40 \%$ (adjusted Hazard Ratio (aHR) 1.40; 95\% confidence interval (CI) 1.10 to 1.79) (Gold 2010). Similarly, Shreffler et al found that women who had experienced stillbirth had a significantly increased risk of divorce post-loss (Odds ratio (OR) 1.70; $\mathrm{P}<0.05)$ (Shreffler 2012). Another study found that for couples with a previous stillbirth, the risk of relationship breakdown was fourfold compared with couples with no history of stillbirth (OR 4.3; $95 \% \mathrm{Cl} 1.6$ to 12.0 ) (Turton 2009). However, this study did not control for important relationship factors, which may partly explain the larger effect of stillbirth on the risk of relationship breakdown.

Perceived partner support after the death of a loved one is well known to be a significant protective factor against lasting grief and distress (Buchi 2009). Couples who share and communicate their grief report less severe grief reactions and greater partner satisfaction (Buchi 2009; Kamm 2001). This suggests that congruent grieving within couples leads to better relationship outcomes and, conversely, that incongruent grief could result in relationship problems. A small, unique study investigated this concept and found that emotional exchange between parents was reflected by concordant grieving in which levels of suffering, depression and anxiety as well as processes of post-traumatic growth were shared by parents. In contrast, parents with disconcordant grief were also disconcordant in suffering, depression and anxiety and did not share post-traumatic growth. Separate, independent experiences of grief, suffering and post-traumatic growth are likely to negatively impact relationship dynamics and satisfaction and may even result in separation (Buchi 2009). Based on the concept of grief concordance, it is not surprising that despite intensified relationship stress, some couples indicate that their loss has "brought them closer together" increasing the relationship cohesion (Cacciatore 2008a; DeFrain 1990).

\section{Fathers}

When a baby dies, mothers generally report more severe and enduring grief than fathers (Murray 2000). However, the more active parenting role of today's fathers is likely to impact on grief intensity. Increased prenatal attachment associated with modern obstetric practices, such as prenatal diagnostic procedures, assisted reproduction and graphic ultrasound imaging, has been reported to increase the intensity of mothers' grief (Robinson 1999); it is therefore reasonable to expect that fathers too may experience more intense grief with increasing attachment.

Research indicates both similar and distinctly different grief responses in mothers and fathers after perinatal death. A review of the effects of perinatal death on fathers (Badenhorst 2006) identified common themes in paternal and maternal grief such as shock, anger, emptiness, helplessness and loneliness. Feelings of guilt were frequently reported by mothers but were rarely reported by men. Although findings on maternal and paternal responses to perinatal death are relatively consistent across studies and provide useful information, studies tend to lack statistical power and design quality. Hence, well-designed studies which take a more systematic approach to identifying affective and behavioural responses that are specific to mothers and fathers are needed.

\section{Interventions}

The narrative review by Forrest 20 years ago (Forrest 1989) on support after a perinatal death highlighted the need for further 
high-quality research in this area. Over time, an abundance of studies have been conducted in the area of perinatal loss, leading to the development of clinical practice guidelines and the widespread development and implementation of a range of support interventions. Common interventions described in the literature include a wide range of medical and psychosocial interventions, provided in both the antenatal and postnatal period.

\section{Prenatal genetic testing}

The death of a baby can occur at any time during the perinatal period, the first of which is during pregnancy. With over 500 prenatal genetic tests currently available and increasingly sophisticated ultrasonography, parents can be informed of the potential risk or diagnosis of a fetal abnormality as early as the first or second trimester of pregnancy. In order to make informed decisions about whether or not to continue the pregnancy, parents need to be provided with clear, unbiased information and receive continuous, compassionate guidance and support throughout the various stages of testing and the decision-making process (Scully 2007).

\section{Termination of pregnancy (TOP)}

Most studies of women who undergo TOP for fetal abnormalities report significant grief within the first four to six months. Although the majority of these women will adapt and recover well, this group has been identified to be at increased risk of complicated grief (Kersting 2004; Korenromp 2005; Zeanah 1993). Recommendations for care include better information and preparation of those women and the development of specific, relevant grief therapy interventions. Physicians and other healthcare providers should inform and prepare women that their loss may have a significant, long-lasting impact (Kersting 2006).

\section{Palliative care}

Perinatal palliative care (PNPC) is an emerging field within the area of perinatal loss which aims to provide care for dying babies and their parents. For some couples it can provide an alternate option to TOP for fetal abnormalities (Breeze 2007). To date, no empirical studies have determined the best model for perinatal palliative care, however, a small number of clinical studies have identified key components to be: early engagement, continuity of antenatal care, a family-centred approach to care, and multi-disciplinary team involvement, including a bereavement specialist. Centres that provide a perinatal hospice or palliative care service report up to $87 \%$ uptake (Balaguer 2012).

Supporting parents in end-of-life decision-making when a baby is dying or when continuation of care is futile, includes clear, compassionate communication, physical and emotional care, collaborative decision making and follow-up care (Williams 2008). Active parental involvement in discussions and decisions about withholding or withdrawing care has not been found to aggravate or prolong parental grief or increase the incidence of grief pathology (Schulze 2007). A model of shared decision-making based on the discussion of mutual 'goals of care' gives equal weight to the family and the medical team and often reduces the potential for conflict (Schulze 2007).

Effective neonatal pain and symptom management, discussing options for parental involvement in the baby's dying, preparation for the death and guided decision-making are important aspects of palliative care (Armentrout 2009; Kaempf 2009; Munson 2007). Common challenges to providing comprehensive end-of-life care include care-giver comfort, consistency of care, cultural and legal barriers, and lack of adequate staff training (Kain 2006).

\section{Birthing options after diagnosis of fetal death}

Following the diagnosis of an intrauterine fetal death (IUFD), most women opt for delivery of the baby within 48 hours (Silver 2010). The timing of delivery depends on a variety of factors and management should be individualised, however, postponing the birth too long may increase maternal psychological distress and anxiety. One study found that women who postponed delivery for more than 24 hours, had a fivefold increased risk of long-term anxiety related symptoms (Radestad 1996).

Mode of birth is largely dependent on fetal gestational age and maternal clinical history, with consideration of the couple's personal preference. Induction or augmentation of labour and natural vaginal birth has the lowest medical risk for women (Villar 2007). Caesarean section should be reserved for women when clinically indicated. Although couples with a diagnosis of IUFD commonly consider a caesarean section as their initial preferred mode of birth (Samuelsson 2001), women with no clinical indication for this procedure should be encouraged to consider a normal labour due to the known increased risks associated with previous caesarean section in a subsequent pregnancy (Flenady 2011b; Lydon-Rochelle 2001; O'Neil 2013). Reassurance should be given to the parents that pain relief and physical and emotional support during labour and birth will be provided.

\section{Pain relief and sedation}

A systematic review on hospital care after perinatal death found that pain relief is often inadequate (Gold 2007a). Yet, sedation is often over-prescribed after perinatal loss (Harper 1994). A large anonymous national survey of obstetricians in the United States revealed that $48.5 \%$ supported the prescription of sedatives for a grieving mother in acute bereavement care (Gold 2008), despite the lack of evidence for its benefit in the improvement of sleep or grief (Warner 2001). Furthermore, a significant body of evidence exists about the potential addictive nature of this group of medications. It is strongly recommended that pharmacological management of grief should only be considered in the presence of an established psychological disorder for which medication is indicated (Raphael, Minkov et al. 2001).

\section{Seeing and holding}

Currently, most best practice guidelines recommend that all parents should be offered a choice about whether or not they want to see and hold their stillborn baby, and that parents should be supported throughout this process (Flenady 2009; NICE 2010; SANDS 2010). However, the evidence around the benefit of holding and seeing remains somewhat controversial, providing no simple directions to guide staff and parents.

A controversial study in the UK of mothers with a subsequent pregnancy following a stillbirth found that seeing and holding a stillborn baby was associated with worse maternal psychological outcomes (Hughes 2002). Mothers who saw their stillborn baby were more likely to experience anxiety in the third trimester of a subsequent pregnancy. By one year postpartum, anxiety had resolved but PTSD symptoms were higher compared with women 
who had not seen their baby. Women who held their stillborn baby were more likely to experience symptoms of PTSD in the third trimester of a subsequent pregnancy and one year after delivery, but this was not the case for depression or anxiety. Followup of the mothers at seven years indicated that higher rates of PTSD symptomatology persisted over time (Turton 2009). The study by Hughes and colleagues has been heavily criticised by both bereaved parents and researchers who feel that the translation of the study results to all women should be made with caution due to issues with cohort representation, small sample size and the lack of detail provided around how women were presented with (the option of seeing or holding) their stillborn baby (Ambuehl 2002; Brooks 2002; Kersting 2002; Matthews 2002; McCabe 2002). Methodological shortcomings of the study, including sample size and inclusion of women in a subsequent pregnancy only who had no other living children, limits the generalisability of the study findings.

In a study on late stillbirths (greater than 28 weeks gestation), nearly all mothers who held their stillbirth baby found the experience valuable (Radestad 2009). Mothers who felt they had not received enough support from hospital staff to hold their baby were four times more likely to have not held their stillborn baby when compared with mothers who felt supported. The importance of perceived staff support and attitudes in influencing parental decision-making about seeing and holding a deceased baby is well documented (Radestad 2009; Ransohoff-Adler 1989; Trulsson 2004).

Anecdotal evidence suggests that bereaved parents have much appreciated the experience of seeing and holding their stillborn baby. Women who experienced a stillbirth in the past have repeatedly come forward in more recent years, expressing their distress about not being allowed to see or hold their stillborn baby at the time and not knowing what happened to their babies' bodies. Despite a lack of empirical evidence, research and opinion papers published on this topic generally agree that holding and seeing a stillborn baby is valuable for most, but not all women, and that staff should hence be mindful and sensitive to the individual needs and wishes of each family (Baker 2009; Radestad 2009; Sloan 2008).

\section{Memory creation}

Activities that support parents in developing a bond with their baby help create a sense of identity of the child (Klass 1996; Klass 1999). Clinical guidelines support activities such as bathing and dressing the baby, talking to the baby and using the baby's name, engaging in religious or naming ceremonies, introducing the baby to extended family, and capturing interactions in photographs and movies. For many parents, it is the experience of parenting, not mementos, which is the most valuable in the creation of a bond.

There is general consensus that bereaved parents should be offered items of memorabilia such as photos, hand/footprints and special clothing or blankets when a baby dies (Gold 2007a; Henley 2008; Radestad 1996; Silver 2010). The collecting of such items does not appear to lead to adverse grief outcomes (Hughes 2002) and not having such items has been linked to increased anxiety in mothers of stillborn babies (Radestad 1996). A meta-analysis of hospital care for parents after a perinatal loss found that parents overwhelmingly appreciated having photos and memorabilia of their deceased baby, and frequently expressed regret if these were not provided by the hospital (Gold 2007a). Fathers reported that tokens of remembrance were invaluable, and were appreciative of staff collecting them, even if they were declined (Radestad 1996; Samuelsson 2001).

\section{Parent information resources and web-based support}

One case-controlled study has demonstrated the benefit of specially designed perinatal grief resources for bereaved families (Murray 1999). Resources included children's story books, and individualised parent information and staff brochures. Web-based mental health services, including informative websites, online selfhelp groups, virtual counselling services and automated therapy programs for specific mental health problems such as posttraumatic stress (Knaevelsrud 2007; Lange 2003) and complicated grief (Wagner 2006), have emerged more recently and may be able to offer useful support options for some parents experiencing perinatal death (Kersting 2009; Kersting 2011a).

Kersting et al ( Kersting 2011a) designed, trialed and assessed an online cognitive behavioural therapy protocol adapted from Wagners Internet-based program for clients suffering from complicated grief, and adjusted it to meet the needs of adult mothers who had recently experienced pregnancy loss (i.e. miscarriage, TOP for fetal anomalies or stillbirth). Compared to controls, the cognitive behavioural therapy group, consisting of mothers who did not have serious mental health problems prior to commencing online cognitive behavioural therapy, showed significant improvements in post-traumatic stress $(P=0.012)$, grief intensity $(P=0.001)$ and overall mental health $(P=0.004)$.

Online support groups and memorial websites have become popular in recent times. It is frequently assumed that such resources can be a useful source of psycho-education and provide a sense of emotional and appraisal support (Glanz 2008) for bereaved individuals, however scientific investigation to back up such claims falls far short of acceptable standards. The potential for damage is frequently neglected, with concerns for exploitation or abuse of the lonely and vulnerable, and the possibility that Internet activity reduces socially interaction, potentially reducing much needed social support for the bereaved. With no randomised controlled trials or criteria or procedures to differentiate high-quality from low-quality Internet resources, the value of such resources cannot be determined, and caution should be taken with recommendation (Stroebe 2008b).

\section{Social support}

The social environment of the griever has been identified as a significant factor in grief outcomes (Doka 1999), and the role of social support in parental grief has been well documented (Hutti 2005; Umphrey 2011; Zeanah 2006). Qualitative studies demonstrate a correlation between support (from doctors, nurses and families) and lower levels of anxiety and depression in mothers following a stillbirth, with family support reported as most significant (Cacciatore 2008b). Support from partners, family and those outside the family has been shown to reduce maternal distress in the long-term (15 months), though not in the short-term (Murray 1999). The role of support groups in perinatal loss is less clear. A few qualitative studies report a range of important benefits, particularly for women (Cacciatore 2007). Despite the potential value for some mothers however, without well-designed studies to measure both qualitative and quantitative outcomes, support groups may not be recommended for all grieving mothers. 


\section{Culturally sensitive care}

The importance of recognising the cultural perspective of loss and grief is well supported in the adult loss and grief literature (Butler 2012; Stroebe 1998; Walter 2010), however only limited attempts have been made to explore the cultural context of perinatal loss. Seminars in Fetal and Neonatal Medicine (October 2008) published a series of discussion papers on cultural perspectives of care in foetal and neonatal medicine, (Evans 2008; Gatrad 2008; Husain 2008; Laing 2008; McGraw 2008; Nelson 2008; Rennie 2008; Shinwell 2008; Steer 2008; Vaughan 2008; Williams 2008). They conclude the importance of sensitive cultural approaches and encourage further research in this area of perinatal care. Others (Chichester 2005; Laing 2008) caution imposing a 'Western grief culture' which values engagement with death and grief onto other cultures. Staff's knowledge and understanding of key religious and cultural rituals can greatly facilitate difficult discussions and decision-making around the time of death of a baby (Gatrad 2008).

\section{Counselling and psychotherapy}

No robust studies have been undertaken in the area of perinatal loss to determine the effect of grief counselling or psychotherapy on parental grief. A recent systematic review of 61 controlled outcome studies of grief counselling in the general bereaved population over the last three decades found only small observed advantages in treated clients compared to untreated controls, effects which are lost over time (Neimeyer 2010). Authors conclude that universally applied bereavement interventions do not achieve measurable benefit when compared with 'no treatment' groups, and the majority of grievers experiencing 'normal' grief will adapt to their loss or respond resiliently (Bonanno 2004; Neimeyer 2010). This is in contrast to high-risk groups such as parents who have lost children, (Neimeyer 2010, p6) or grievers with significant symptomatolgy, such as those with complicated grief or clinical depression, who do receive benefit. The task for primary clinicians in the area of parental bereavement will be to identify parents who are at increased risk of pathological grief, and who would benefit from referral to mental health services.

There is no doubt that compassionate, sensitive care is invaluable for bereaved parents and families (Janzen 2003-2004; Kirkley-Best 1982; Mashegoane 1999; Murray 2000; Wing 2001). The importance of appropriate psychosocial support for all women and families globally was recently highlighted in a comprehensive international stillbirth series published in the Lancet (Froen 2011; Flenady 2011a, as part of www.thelancet.com/series/stillbirth [Lancet Stillbirth series 2011]). Yet, what continues to pose difficulties for those attempting to provide perinatal bereavement support is exactly what it is that comprises 'best practice', particularly in relation to psychosocial care. We undertook this review to identify evidence from high quality randomised controlled trials, looking at optimal approaches for supporting parents and families experiencing perinatal death.

\section{O B J E C T IVES}

The specific objectives of this review are to determine the effectiveness of any form of medical, midwifery, nursing, psychological or social support in preventing or reducing the incidence or severity, or both, of (protracted) grief reactions or longterm psychopathological sequelae, or both, in mothers, fathers and families experiencing perinatal death.

\section{METHODS}

\section{Criteria for considering studies for this review}

\section{Types of studies}

Randomised controlled trials were considered for inclusion in this review if:

- perinatal death was defined as stillbirth or neonatal death according to the definitions used in each trial;

- the study compared any social or professional support, or both, after perinatal death, with standard care as practiced at the time of the study;

- the proportion of loss to follow-up was no more than $30 \%$.

\section{Types of participants}

Mothers and/or fathers and/or their immediate families, experiencing the death of a baby in the perinatal period. Trials involving early spontaneous pregnancy losses (i.e. spontaneous miscarriages before 20 weeks' gestation or as according to the definition of miscarriage used in each trial) or termination of pregnancy (TOP) for non-medical reasons were excluded.

\section{Types of interventions}

Any type of intervention provided by professional or nonprofessional individuals or groups which are aimed at improving the psychological well-being of parents and families after perinatal death. These may include any form of:

- general supportive hospital interventions aimed at supporting parents around the time of their baby's death. This may include parent information provision after a stillbirth diagnosis or diagnosis of a fetal abnormality, photographs and other memorabilia, holding and naming the baby, offering dignified funeral rites or disposal arrangements for stillbirths, and hospital follow-up visits;

- specific religious, spiritual and/or cultural supports;

- interventions labelled as bereavement counselling;

- specialised psychotherapy, counselling, or assessment, either single or multiple sessions or therapeutic episodes;

- interventions for women with a previous perinatal death in the subsequent pregnancy;

- community and online support groups.

\section{Types of outcome measures}

\section{Primary outcomes}

The primary outcome measures include:

- normal grief reactions including depressed mood and anxiety;

- pathological grief reactions, including post-traumatic stress and complicated grief;

- satisfaction with care.

\section{Secondary outcomes}

Secondary outcome measures include:

- physical symptoms of grief;

- signs of social maladjustment;

- family disruption; relationship disharmony or breakdown; 
- cost of interventions.

Where appropriate, these outcomes are definable by standard clinical criteria and measurable by standard psychometric methods such as questionnaires or interviews, or both. Where possible, we planned that subgroup analyses of outcomes for high-risk groups would be conducted (i.e. women with TOP for fetal abnormality, poor support and subsequent pregnancy).

\section{Search methods for identification of studies}

\section{Electronic searches}

We searched the Cochrane Pregnancy and Childbirth Group's Trials Register by contacting the Trials Search Co-ordinator (28 January 2013).

The Cochrane Pregnancy and Childbirth Group's Trials Register is maintained by the Trials Search Co-ordinator and contains trials identified from:

1. monthly searches of the Cochrane Central Register of Controlled Trials (CENTRAL);

2. weekly searches of MEDLINE;

3. weekly searches of EMBASE;

4. handsearches of 30 journals and the proceedings of major conferences; and

5. weekly current awareness alerts for a further 44 journals plus monthly BioMed Central email alerts.

Details of the search strategies for CENTRAL, MEDLINE and EMBASE, the list of handsearched journals and conference proceedings, and the list of journals reviewed via the current awareness service can be found in the 'Specialized Register' section within the editorial information about the Cochrane Pregnancy and Childbirth Group.

Trials identified through the searching activities described above are each assigned to a review topic (or topics). The Trials Search Coordinator searches the register for each review using the topic list rather than keywords.

\section{Searching other resources}

We searched reference lists of retrieved articles.

We did not apply any language restrictions.

\section{Data collection and analysis}

For the methods used when assessing trials identified in the previous version of this review, see Appendix 1.

\section{Selection of studies}

Two review authors independently assessed for inclusion all the potential studies we identified as a result of the search strategy. We planned to resolve any disagreement through discussion or, if required, we planned to consult a third person.

When information regarding any of the above was unclear, we contacted authors of the original reports to provide further details.

In future updates, we will use the methods for assessing eligibility, data extraction and management, risk of bias, and data synthesis described in the Cochrane Handbook for Systematic Reviews of Interventions (Higgins 2011) and set out in detail in Appendix 2.

\section{RES U LTS}

\section{Description of studies}

One new trial was identified (Kersting 2011b). However, the data format reported in this trial did not allow us to separate out treatment outcomes for women who had a stillbirths or late TOP for fetal abnormalities from women who had miscarriages or early TOP. The author of the trial was contacted with the request to kindly provide, if possible, study findings specific to women who had a stillbirth or late TOP for fetal abnormalities. Pending the response, this trial is currently awaiting classification for the purposes of this review (see table Characteristics of studies awaiting classification).

In the previous version the authors identified three potentially eligible trials (Forrest 1982; Lake 1987; Lilford 1994) but these were all excluded (see table Characteristics of excluded studies). The large loss to follow-up rate was the major reason for exclusion.

\section{Risk of bias in included studies}

Not applicable.

\section{Effects of interventions}

Not applicable.

\section{DISCUSSION}

This review has highlighted the difficulty of research in the area of grief support around the time of perinatal death, and the ongoing lack of empirical evidence that has arisen from existing studies. From being largely neglected in the past, it is encouraging to see some randomised controlled trials being undertaken to address the lack of high level evidence. However, the available empirical data remains sparse and variable, and trials are of insufficient quality, size and comparability to enable any truly valid conclusions.

One of the excluded trials (Lake 1987) was set in a population of predominantly indigent single or poorly socially-supported mothers, or both, in west central Florida, while the other two (Forrest 1982; Lilford 1994) were set in large British teaching hospitals and included partners in the intervention. The most recent trial (Lilford 1994) was the only one that included couples who had experienced termination of pregnancy (TOP) for fetal anomaly as well as stillbirths and neonatal deaths.

The three excluded trials (see table Characteristics of excluded studies) do however provide some insight into the areas of difficulties in these studies, and may guide the design of future trials. Only one trial (Lilford 1994) provided power calculations of the numbers needed to be randomised, and the results of this trial could be utilised towards better estimation of the numbers required in future studies to retest the hypothesis. The large loss to follow-up rate was the major reason for exclusion of all three trials, and should alert future researchers to specifically target this problem and to seek sufficient resources to enable better follow-up.

All three trials identified certain high-risk groups that may warrant further study. Two (Forrest 1982; Lake 1987) noted that sociallyisolated women or women with low levels of social support tended to have a higher incidence of psychiatric symptoms. One trial (Lilford 1994), suggested that women who underwent TOP for fetal anomalies had slightly worse outcomes than those who had 
experienced stillbirth or neonatal death. This is likely to be related to the specific grief issues related to TOP, including active decision making, guilt and shame. Given the difficulty of research in this area, it may be that specific emphasis and attention to these highrisk groups, with adequate levels of follow-up, may be warranted.

Although two trials (Forrest 1982; Lilford 1994) included partners in the interventions, they were not able to draw any specific conclusions and further attention to the effects of such interventions for fathers is needed.

The influence of cultural and racial differences on the incidence of psychiatric symptoms remains a potentially interesting but unexplored aspect of adjustment to perinatal death and as yet no randomised controlled trials have specifically addressed this issue.

The current discussion and planning towards the inclusion of complicated or pathological grief as a distinct category of mental disorder in the upcoming Diagnostic and Statistical Manual of Mental Disorders (DSM-V) will have implications on both the identification and potential interventions for bereaved parents (Zhang 2006). Clarity of the definition and classification of pathological grief is likely to increase the identification of a population for whom intervention is likely to be helpful, and this in turn is likely to lead to the development of interventions that can be empirically tested.

Another emerging area of research that will contribute to our scientific knowledge of grief interventions is that of the neurobiology of grief and trauma indicating that grief is mediated through a neural network across regions of the brain (Gündel 2003).

Also, growing research into resilience (Zhang 2006) and posttraumatic growth (Buchi 2007) will add further to the development of effective post-loss interventions.

\section{AUTHORS' CONCLUSIONS}

\section{Implications for practice}

Due to the lack of randomised trials in this area, this review cannot provide clear guidance for best practice in the area of support for parents and families following a stillbirth or neonatal death. Nontheless, providing support for parents and families after perinatal death is justified based on the study findings of nonrandomised studies discussed in this review, and the authors have highlighted a range of interventions that may be useful to parents and families. It is evident from this review that three themes are consistent in providing care for bereaved parents: firstly a deep respect for the individuality and diversity of grief, respect for the deceased child, and recognition of the healing power and resilience of the human spirit.

\section{Implications for research}

Methodologically rigorous trials are needed in order to assess the true effects of interventions aimed at providing appropriate and sensitive support for parents and families after a perinatal death. Certain high-risk groups (women with pre-existing mental health issues, women with termination of pregnancy) may need to be specifically targeted, as will the effect of interventions for fathers. It is likely that multi-centre studies will be necessary, with adequate funding to ensure proper follow-up in order to definitively address these questions. Further, trials should ensure that the range of outcome measures is clearly defined and is assessed by standard psychometric tools, as far as possible validated for the purpose, that data are numerically complete and appropriately presented, and that adequate follow-up is possible.

\section{ACK N O WLEDGEMENTS}

The authors acknowledge Helen Chambers for undertaking the original version of this review in collaboration with Fung Yee Chan, and Vicki Flenady and Trish Wilson for revising the second version. The authors dedicate this review to Professor Fung Yee Chan who passed away in May 2007.

The authors would like to thank Therese Dowswell, Lynn Hampson, Denise Atherton, Sonja Henderson and Fran Kellie from the Pregnancy and Childbirth Group for their advice and support and their help with the preparation of this manuscript.

Lastly, the authors wish to acknowledge the many bereaved parents who have graciously and willingly participated in clinical research at one of the most difficult times of their lives, in order to assist researchers and clinicians to provide high-quality, sensitive and respectful care.

The National Institute for Health Research (NIHR) is the largest single funder of the Cochrane Pregnancy and Childbirth Group. The views and opinions expressed therein are those of the authors and do not necessarily reflect those of the NIHR, NHS or the Department of Health. 


\section{RE F E R E N C E S}

\section{References to studies excluded from this review}

Forrest 1982 \{published data only\}

Forrest GC, Standish E, Baum JD. Support after perinatal death: a study of support and counselling after perinatal bereavement. British Medical Journal 1982;285(6353):1475-9.

\section{Lake 1987 \{published data only\}}

Lake MF, Johnson TM, Murphy J, Knuppel RA. Evaluation of a perinatal grief support team. American Journal of Obstetrics and Gynecology 1987;157(5):1203-6.

\section{Lilford 1994 \{published data only\}}

Lilford RJ, Stratton P, Godsil S, Prasad A. A randomised trial of routine versus selective counselling in perinatal bereavement from congenital disease. British Journal of Obstetrics and Gynaecology 1994;101(4):291-6.

\section{References to studies awaiting assessment}

Kersting 2011b \{published and unpublished data\} Kersting A, Kroker K, Schlicht S, Baust K, Wagner B. Efficacy of cognitive behavioral internet-based therapy in parents after the loss of a child during pregnancy: pilot data from a randomized controlled trial. Archives of Women's Mental Health 2011;14(6):465-77.

\section{Additional references}

\section{Ambuehl 2002}

Ambuehl E. Psychosocial care of mothers after stillbirth. Lancet 2002;360(9345):1601; author reply 1601-2.

\section{Armentrout 2009}

Armentrout D. Living with grief following removal of infant life support: parents' perspectives. Critical Care Nursing Clinics of North America 2009;21(2):253-65.

\section{Badenhorst 2006}

Badenhorst W, Riches S, Turton P, Hughes P. The psychological effects of stillbirth and neonatal death on fathers: systematic review. Journal of Psychosomatic Obstetrics and Gynaecology 2006;27(4):245-56

\section{Badenhorst 2007}

Badenhorst W, Hughes P. Psychological aspects of perinatal loss. Best Practice and Research. Clinical Obstetrics and Gynaecology 2007;21(2):249-59.

\section{Baker 2009}

Baker AM, Crandall L. To hold or not to hold. Forensic Science, Medicine and Pathology 2009;5(4):321-3.

\section{Balaguer 2012}

Balaguer A, Martin-Ancel A, Ortigoza-Escobar D, Escribano J, Argemi J. The model of palliative care in the perinatal setting: a review of the literature. BMC Pediatric 2012;12:25.

\section{Bonanno 2001}

Bonanno GA, Kaltman S. The varieties of grief experience. Clinical Psychology Review 2001;21(5):705-34.

\section{Bonanno 2004}

Bonanno GA. Loss, trauma, and human resilience: have we underestimated the human capacity to thrive after extremely aversive events?. American Psychologist 2004;59(1):20-8.

\section{Breeze 2007}

Breeze ACG, Lees CC, Kumar A, Missfelder-Lobos HH, Murdoch EM. Palliative care for prenatally diagnosed lethal fetal abnormality. Archives of Disease in Childhood. Fetal and Neonatal Edition 2007;92(1):F56-F58.

\section{Brooks 2002}

Brooks D. Psychosocial care of mothers after stillbirth. Lancet 2002;360(9345):1601; author reply 1601-2.

\section{Buchi 2007}

Buchi S, Morgeli H, Schnyder U, Jenewein J, Hepp U, Jina E, et al. Grief and post-traumatic growth in parents 2-6 years after the death of their extremely premature baby. Psychotherapy and Psychosomatics 2007;76(2):106-14.

\section{Buchi 2009}

Buchi S, Morgeli H, Schnyder U, Jenewein J, Glaser A, Fauchere JC, et al. Shared or discordant grief in couples 2-6 years after the death of their premature baby: effects on suffering and posttraumatic growth. Psychosomatics 2009;50(2):123-30.

\section{Burnett 1997}

Burnett P, Middleton W, Raphael B, Martinek N. Measuring core bereavement phenomena. Psychological Medicine 1997;27(1):49-57.

\section{Butler 2012}

Butler RJ, Neimeyer RA. Constructions of death and loss: a personal and professional evolution. Reflections in Personal Construct Theory. Chichester, West Sussex, UK: John Wiley \& Sons Ltd, 2012.

\section{Cacciatore 2007}

Cacciatore J. Effects of support groups on post traumatic stress responses in women experiencing stillbirth. Omega (Westport) 2007;55(1):71-90

\section{Cacciatore 2008a}

Cacciatore J, DeFrain J, Jones KLC, Jones H. Stillbirth and the couple: a gender-based exploration. Journal of Family Social Work 2008;11(4):351-70.

\section{Cacciatore 2008b}

Cacciatore J, Radestad I, Froen F. Effects of contact with stillborn babies on maternal anxiety and depression. Birth 2008;35(4):313-20. 


\section{Chichester 2005}

Chichester M. Multicultural issues in perinatal loss. AWHONN Lifelines/Association of Women's Health, Obstetric and Neonatal Nurses 2005;9(4):312-20.

\section{DeFrain 1990}

DeFrain J, Martens L, Stork J, Stork W. The psychological effects of a stillbirth on surviving family members. Omega: Journal of Death and Dying 1990;22(2):81-108.

\section{Doka 1999}

Doka KJ. Disenfranchised grief. Bereavement Care 1999;18(3):37-9.

\section{Evans 2008}

Evans N. Reorientation of care in the NICU: an Australian perspective. Seminars in Fetal and Neonatal Medicine 2008;13(5):311-2.

\section{Fish 1986}

Fish W. Differences in grief intensity in bereaved parents. Champaigne, IL: Research Press Company, 1986.

\section{Flenady 2009}

Flenady V, King J, Charles A, Gardener G, Ellwood D, Day K, et al. PSANZ Clinical practice guideline for perinatal mortality. Perinatal Mortality Grouphttp://www.psanzpnmsig.org.au. Perinatal Society of Australia and New Zealand, April 2009; Vol. Version 2.2.

\section{Flenady 2011a}

Flenady V, Middleton P, Smith GC, Duke W, Erwich JJ, Khong TY, et al. Stillbirths: the way forward in high-income countries. Lancet 2011;377(9778):1703-17.

\section{Flenady 2011b}

Flenady V, Koopmans L, Middleton P, Frøen JF, Smith GC, Gibbons K, et al. Major risk factors for stillbirth in high-income countries: a systematic review and meta-analysis. Lancet 2011;377(9774):1331-40.

\section{Forrest 1989}

Forrest G. Care of the bereaved after perinatal death. In Chalmers I, Enkin MW, Keirse MJNC editor(s). Effective Care in Pregnancy and Childbirth. Oxford: Oxford University Press, 1989:1423-30.

\section{Froen 2011}

Froen JF, Cacciatore J, McClure EM, Kuti O, Jokhio AH, Islam M, et al. Stillbirths: why they matter. Lancet 2011;377(9774):1353-66.

\section{Gatrad 2008}

Gatrad AR, Muhammad BJ, Sheikh A. Reorientation of care in the NICU: a Muslim perspective. Seminars in Fetal and Neonatal Medicine 2008;13(5):312-4.

\section{Giles 1970}

Giles P. Reactions of women to perinatal death. Australian and New Zealand Journal of Obstetrics and Gynaecology 1970;10(4):207-10.

\section{Glanz 2008}

Glanz K, Rimer BK, Viswanath K. Health Behavior and Health Education: Theory, Research, and Practice. San Francisco CA, US: Jossey-Bass, 2008.

\section{Gold 2007a}

Gold KJ, Dalton VK, Schwenk TL. Hospital care for parents after perinatal death. Obstetrics and Gynecology 2007;109(5):1156-66.

\section{Gold 2008}

Gold KJ, Schwenk TL, Johnson TRB. Brief report: sedatives for mothers of stillborn infants: views from a national survey of obstetricians. Journal of Women's Health 2008;17(10):1605-7.

\section{Gold 2010}

Gold, KJ, Sen A, Hayward RA. Marriage and cohabitation outcomes after pregnancy loss. Pediatrics 2010;125(5):e1202e1207.

\section{Gravensteen 2012}

Gravensteen IK, Helgadottir LB, Jacobsen EM, Sandset PM, Ekeberg $\varnothing$. Long-term impact of intrauterine fetal death on quality of life and depression: a case-control study. BMC Pregnancy and Childbirth 2012;12:43.

\section{Gündel 2003}

Gündel H, O'Connor MF, Littrel L, Fort C, Lane RD. Functional neuroanatomy of grief: an fMRI study. American Journal of Psychiatry 2003;160(11):1946-53.

\section{Harper 1994}

Harper MB, Wisian NB. Care of bereaved parents: a study of patient satisfaction. Journal of Reproductive Medicine 1994;39(2):80-6.

\section{Henley 2008}

Henley A, Schott J. The death of a baby before, during or shortly after birth: good practice from the parents' perspective. Seminars in Fetal and Neonatal Medicine 2008;13(5):325-8.

\section{Higgins 2011}

Higgins JPT, Green S (Eds). Cochrane Handbook for Systematic Reviews of Interventions. Version 5.1.0 [updated March 2011]. The Cochrane Collaboration. Available from www.cochranehandbook.org 2011.

\section{Hughes 2002}

Hughes P, Turton P, Hopper E, Evans CDH. Assessment of guidelines for good practice in psychosocial care of mothers after stillbirth: a cohort study. Lancet 2002;360(9327):114-8.

\section{Hughes 2003}

Hughes P, Riches S. Psychological aspects of perinatal loss. Current Opinion in Obstetrics and Gynecology 2003;15(2):107-11.

\section{Husain 2008}

Husain F. Ethical dimensions of non-aggressive fetal management: a Muslim perspective. Seminars in Fetal and Neonatal Medicine 2008;13(5):323-4. 


\section{Hutti 2005}

Hutti MH. Social and professional support needs of families after perinatal loss. Journal of Obstetric, Gynecologic and Neonatal Nursing 2005;34(5):630-8.

\section{Janzen 2003-2004}

Janzen L, Cadell S, Westhues A. From death notification through the funeral: bereaved parents' experience and their advice to professionals. Omega: Journal of Death and Dying 2003-2004;48(2):149-64.

\section{Kaempf 2009}

Kaempf JW, Tomlinson MW, Campbell B, Ferguson L, Stewart VT. Counseling pregnant women who may deliver extremely premature infants: medical care guidelines, family choices, and neonatal outcomes. Pediatrics 2009;123(6):1509-15.

\section{Kain 2006}

Kain VJ. Palliative care delivery in the NICU: what barriers do neonatal nurses face?. Neonatal Network 2006;25(6):387-92.

\section{Kamm 2001}

Kamm S, van den Berg B. Grief communication, grief reactions, and marital satisfaction in bereaved parents. Death Studies 2001;25(7):569-82.

\section{Keane 2009}

Keane TM, Marx BP, Sloan DM. Post-traumatic stress disorder: definition, prevalence, and risk factors. In: Shiromani PJ, Keane TM, LeDoux JE editor(s). Post-traumatic Stress Disorder: Basic Science and Clinical Practice. New York: Humana Press, 2009:1-19.

\section{Kennell 1970}

Kennell JH, Slyter J, Klaus MH. The mourning responses of parents to the death of a newborn infant. New England Journal of Medicine 1970;283(7):344-9.

\section{Kersting 2002}

Kersting A, Fisch S, Baez E. Psychosocial care of mothers after stillbirth. Lancet 2002;360(9345):1600; author reply 1601-2.

\section{Kersting 2004}

Kersting A, Reutemann M, Ohrmann P, Baez E, Klockenbusch W, Lanczik M, et al. Grief after termination of pregnancy due to fetal malformation. Journal of Psychosomatic Obstetrics and Gynaecology 2004;25(2):163-9.

\section{Kersting 2006}

Kersting A, Kroker K, Steinhard J. Does abortion technique influence the course of perinatal grief in second trimester termination for fetal anomalies?. American Journal of Obstetrics and Gynecology 2006;194(6):1743.

\section{Kersting 2007}

Kersting A, Kroker K, Steinhard J, Ludorff K, Wesselmannn U, Ohrmann P, et al. Complicated grief after traumatic loss: a 14month follow up study. European Archives of Psychiatry and Clinical Neuroscience 2007;257(8):437-43.

\section{Kersting 2009}

Kersting A, Schlicht S, Kroker K. [Internet therapy. Opportunities and boundaries]. Nervenarzt 2009;80(7):797-804.

\section{Kersting 2011a}

Kersting A, Kroker K, Schlicht S, Wagner B. Internet-based treatment after pregnancy loss: concept and case study. Journal of Psychosomatic Obstetrics \& Gynecology 2011;32(2):72-8.

\section{Kirkley-Best 1982}

Kirkley-Best E, Kellner KR. The forgotten grief: a review of the psychology of stillbirth. American Journal of Orthopsychiatry 1982;52(3):420-9.

\section{Klass 1996}

Klass D, Silverman PR, Nickman SL. Continuing Bonds: New Understandings of Grief. Philadelphia PA, US: Taylor \& Francis, 1996.

\section{Klass 1999}

Klass D. The Spiritual Lives of Bereaved Parents. Philadelphia, US: Brunner/Mazel, 1999.

\section{Knaevelsrud 2007}

Knaevelsrud C, Maercker A. Internet-based treatment for PTSD reduces distress and facilitates the development of a strong therapeutic alliance: a randomized controlled clinical trial. BMC Psychiatry 2007;7:13.

\section{Korenromp 2005}

Korenromp MJ, Page-Christiaens GC, van den Bout J, Mulder EJ, Hunfeld JA, Bilardo CM, et al. Psychological consequences of termination of pregnancy for fetal anomaly: similarities and differences between partners. Prenatal Diagnosis 2005;25(13):1226-33.

\section{Korenromp 2007}

Korenromp MJ, Page-Christiaens GC, van den Bout J, Mulder EJ, Hunfeld JA, Potters CM, et al. A prospective study on parental coping 4 months after termination of pregnancy for fetal anomalies. Prenatal Diagnosis 2007;27(8):709-16.

\section{Laing 2008}

Laing IA, Freer Y. Reorientation of care in the NICU. Seminars in Fetal and Neonatal Medicine 2008;13(5):305-9.

\section{Lancet Stillbirth series 2011}

Stillbirth series. Lancet. Available from www.thelancet.com/ series/stillbirth 2011.

\section{Lange 2003}

Lange A, Rietdijk D, Hudcovicova M, van de Ven JP, Schrieken B, Emmelkamp PM. Interapy: a controlled randomized trial of the standardized treatment of posttraumatic stress through the internet. Journal of Consulting and Clinical Psychology 2003;71(5):901-9.

\section{Lichtenthal 2004}

Lichtenthal WG, Cruess DG, Prigerson HG. A case for establishing complicated grief as a distinct mental disorder in DSM-V. Clinical Psychology Review 2004;24(6):637-62. 


\section{Lydon-Rochelle 2001}

Lydon-Rochelle M, Holt VL, Easterling TR, Martin DP. Risk of uterine rupture during labor among women with a prior cesarean delivery. New England Journal of Medicine 2001;345(1):3-8.

\section{Mashegoane 1999}

Mashegoane S, Mabasa L, Mashego T. Stillbirth grief in hospital settings: assessing the intervention practices of professional helpers. In: Madu S, Baguma P, Pritz A editor(s). Cross-cultural Dialogue on Psychotherapy in Africa. Sovenga, South Africa: UNIN Pres, 1999:374.

\section{Matthews 2002}

Matthews M, Kohner N. Psychosocial care of mothers after stillbirth. Lancet 2002;360(9345):1600; author reply 1601-2.

\section{McCabe 2002}

McCabe A. Psychosocial care of mothers after stillbirth. Lancet 2002;360(9345):1600-1; author reply 1601-2.

\section{McGraw 2008}

McGraw M, Perlman J. Reorientation of care in the NICU: a United States perspective. Seminars in Fetal and Neonatal Medicine 2008;13(5):310-1.

\section{Munson 2007}

Munson D. Withdrawal of mechanical ventilation in pediatric and neonatal intensive care units. Pediatric Clinics of North America 2007;54(5):773-85, xii.

\section{Murray 1999}

Murray JA, Terry DJ. Parental reactions to infant death:the effects of resources and coping. Journal of Social and Clinical Psychology 1999;18(3):341-69.

\section{Murray 2000}

Murray JA, Terry DJ, Vance JC, Battistutta D, Connolly Y. Effects of a program of intervention on parental distress following infant death. Death Studies 2000;24(4):275-305.

\section{Najman 1993}

Najman JM, Vance JC, Boyle F, Embleton G, Foster B, Thearle J. The impact of a child death on marital adjustment. Social Science and Medicine 1993;37(8):1005-10.

\section{Neimeyer 2010}

Neimeyer RA. Grief counselling and therapy: the case for humility. Bereavement Care 2010;29(1):4-7.

\section{Nelson 2008}

Nelson LJ. United States law and managing the terminally ill fetus and newborn. Seminars In Fetal and Neonatal Medicine 2008;13(5):301-4.

\section{NICE 2010}

Anonymous. NICE set to change its advice on holding stillborn babies. Paediatric Nursing 2010;22(2):5.

\section{O'Neil 2013}

O'Neill SM, Kearney PM, Kenny LC, Khashan AS, Henriksen TB, Lutomski JE, et al. Caesarean delivery and subsequent stillbirth or miscarriage: systematic review and meta-analysis. PLoS One 2013;8(1):e54588.

\section{Parkes 1972}

Parkes CM. Bereavement: Studies of Grief in Adult Life. London: Tavistock, 1972.

\section{Radestad 1996}

Radestad I, Steineck G, Nordin C, Sjogren B. Psychological complications after stillbirth: influence of memories and immediate management: population based study. British Medical Journal 1996;312(7045):1505-8.

\section{Radestad 2009}

Radestad I, Surkan PJ, Steineck G, Cnattingius S, Onelov E, Dickman PW. Long-term outcomes for mothers who have or have not held their stillborn baby. Midwifery 2009;25(4):422-9.

\section{Ransohoff-Adler 1989}

Ransohoff-Adler M, Berger CS. When newborns die: do we practice what we preach?. Journal of Perinatology 1989;9(3):311-7.

\section{Raphael 1984}

Raphael, B. The Anatomy of Bereavement: A Handbook for the Caring Professions. London: Hutchinson, 1984.

\section{Rennie 2008}

Rennie JM, Leigh B. The legal framework for end-of-life decisions in the UK. Seminars in Fetal and Neonatal Medicine 2008;13(5):296-300.

\section{RevMan 2012 [Computer program]}

The Nordic Cochrane Centre, The Cochrane Collaboration. Review Manager (RevMan). Version 5.2. Copenhagen: The Nordic Cochrane Centre, The Cochrane Collaboration, 2012.

\section{Robinson 1999}

Robinson M, Baker L, Nackerud L. The relationship of attachment theory and perinatal loss. Death Studies 1999;23(3):257-70.

\section{Samuelsson 2001}

Samuelsson M, Radestad I, Segesten K. A waste of life: fathers' experience of losing a child before birth. Birth 2001;28(2):124-30

\section{SANDS 2010}

Stillbirth, Neonatal Death Support (SANDS). Seeing and holding your baby - Campaign update. http://www.uk-sands.org/ improving-care/information-for-health-professionals/seeingand-holding-a-stillborn-baby-update.html 2010 June 25.

\section{Schulze 2007}

Schulze A, Wermuth I. Compassionate care for terminally ill term and preterm infants. Zeitschrift fur Geburtshilfe und Neonatologie 2007;211(2):54-9. 


\section{Scully 2007}

Scully JL, Porz R, Rehmann-Sutter C. 'You don't make genetic test decisions from one day to the next': using time to preserve moral space. Bioethics 2007;21(4):201-17.

\section{Shear 2005}

Shear, K, Frank E, Houck PR, Reynolds CF. Treatment of complicated grief: a randomized controlled trial. JAMA 2005;293(21):2601-8.

\section{Shear 2011}

Shear, MK, Simon N, Wall M, Zisook S, Neimeyer R, Duan N, et al. Complicated grief and related bereavement issues for DSM-5. Depression and Anxiety 2011;28(2):103-17.

\section{Shinwell 2008}

Shinwell ES, Shinwell AR. Reorientation of care in the NICU: a Jewish perspective. Seminars in Fetal and Neonatal Medicine 2008;13(5):314-5.

\section{Shreffler 2012}

Shreffler K, Hill T, Cacciatore J. The impact of infertility, miscarriage, stillbirth, and child death on marital dissolution. Journal of Divorce and Remarriage 2012;53(2):91-107.

\section{Silver 2010}

Silver RM, Heuser CC. Stillbirth workup and delivery management. Clinical Obstetrics and Gynecology 2010;53(3):681-90.

\section{Sloan 2008}

Sloan EP, Kirsh S, Mowbray M. Viewing the fetus following termination of pregnancy for fetal anomaly. Journal of Obstetric Gynecologic and Neonatal Nursing 2008;37(4):395-404.

\section{Steer 2008}

Steer P. Ethical dimensions of non-aggressive fetal management: a UK perspective. Seminars in Fetal and Neonatal Medicine 2008;13(5):320-1.

\section{Stroebe 1998}

Stroebe M, Schut H. Culture and grief. Bereavement Care 1998;17(1):7-11.

\section{Stroebe 2008a}

Stroebe M, Hansson R, Schut H, Stroebe W. Handbook of Bereavement Research and Practice. Washington DC: American Psychological Association, 2008.

\section{Stroebe 2008b}

Stroebe M, van der Houwen K, Schut H. Bereavement support, intervention and research on the internet: a critical review. In: Stroebe M, Hansson R, Schut H, Stroebe W editor(s). Handbook of Bereavement Research and Practice. Advances in Theory and Intervention. Washington DC, US: American Psychological Association, 2008.

\section{Trulsson 2004}

Trulsson O, Radestad I. The silent child: mothers' experiences before, during, and after stillbirth. Birth 2004;31(3):189-95.

\section{Turton 2001}

Turton P, Hughes P, Evans CD, Fainman D. The incidence and significance of post traumatic stress disorder in the pregnancy after stillbirth. British Journal of Psychiatry 2001;178:556-60.

\section{Turton 2009}

Turton P, Evans C, Hughes P. Long-term psychosocial sequelae of stillbirth: phase II of a nested case-control cohort study. Archives of Women's Mental Health 2009;12(1):35-41.

\section{Umphrey 2011}

Umphrey LR, Cacciatore J. Coping with the ultimate deprivation: narrative themes in a parental bereavement support group. Omega (Westport) 2011;63(2):141-60.

\section{Vance 2002}

Vance JC, Boyle FM, Najman JM, Thearle MJ. Couple distress after sudden infant or perinatal death: a 30-month follow up. Journal of Paediatrics and Child Health 2002;38(4):368-72.

\section{Vaughan 2008}

Vaughan J. Ethical dimensions of non-aggressive fetal management: an Australian perspective. Seminars in Fetal and Neonatal Medicine 2008;13(5):321-3.

\section{Villar 2007}

Villar J, Carroli G, Zavaleta N, Donner A, Wojdyla D, Faundes A, et al. Maternal and neonatal individual risks and benefits associated with caesarean delivery: multicentre prospective study. BMJ (Clinical Research Edition) 2007;335(7628):1025.

\section{Wagner 2006}

Wagner B, Knaevelsrud C, Maercker A. Internet-based cognitivebehavioral therapy for complicated grief: a randomized controlled trial. Death Studies 2006;30(5):429-53.

\section{Walter 2010}

Walter T. Grief and culture: a checklist. Bereavement Care 2010;29(2):5-9.

\section{Warner 2001}

Warner J, Metcalfe C, King M. Evaluating the use of benzodiazepines following recent bereavement. British Journal of Psychiatry 2001;178(1):36-41.

\section{Williams 2008}

Williams C, Munson D, Zupancic J, Kirpalani H. Supporting bereaved parents: practical steps in providing compassionate perinatal and neonatal end-of-life care: a North American perspective. Seminars In Fetal \& Neonatal Medicine 2008;13(5):335-40.

\section{Wing 2001}

Wing D, Clance P, Burge-Callaway K, Armistead L. Understanding gender difference in bereavement following the death of an infant: implications for treatment. Psychotherapy 2001;38(1):60-72.

\section{Zeanah 1993}

Zeanah CH, Dailey JV, Rosenblatt MJ, Saller DN. Do women grieve after terminating pregnancies because of fetal 
anomalies? A controlled investigation. Obstetrics and Gynecology 1993;82(2):270-5.

\section{Zeanah 2006}

Zeanah $\mathrm{CH}$, Harmon RJ. Perinatal loss and infant mental health: an introduction. Infant Mental Health Journal 2006;16(2):76-9.

\section{Zhang 2006}

Zhang B, El-Jawahri A, Prigerson H. Update on bereavement research: evidence-based guidelines for the diagnosis and treatment of complicated bereavement. Journal of Palliative Medicine 2006;9(5):1188-203.

\section{CHARACTERISTICS OF STUDIES}

Characteristics of excluded studies [ordered by study ID]

\section{References to other published versions of this review Chambers 1998}

Chambers HM, Chan FY. Support for women/families after perinatal death. Cochrane Database of Systematic Reviews 1998, Issue 2. [DOI: 10.1002/14651858.CD000452]

\section{Flenady 2008}

Flenady V, Wilson T. Support for mothers, fathers and families after perinatal death. Cochrane Database of Systematic Reviews 2008, Issue 1. [DOI: 10.1002/14651858.CD000452.pub2]

\begin{tabular}{|c|c|}
\hline Study & Reason for exclusion \\
\hline \multirow[t]{2}{*}{ Forrest 1982} & $\begin{array}{l}\text { High loss to follow-up, particularly in treatment group. At } 6 \text { months, the loss to follow-up in the } \\
\text { treatment group was } 36 \% \text { and in the control group, } 24 \% \text {. }\end{array}$ \\
\hline & 25 women were randomised to the treatment group and 25 to the control group. \\
\hline \multirow[t]{3}{*}{ Lake 1987} & $\begin{array}{l}\text { Overall high loss to follow-up. At } 6 \text { months, } 44 \text { women (56.4\%) of the } 78 \text { women recruited were lost } \\
\text { to follow-up. }\end{array}$ \\
\hline & Randomisation method not stated. \\
\hline & Data available are in an unsuitable form for analysis. \\
\hline \multirow[t]{3}{*}{ Lilford 1994} & $\begin{array}{l}\text { High loss to follow-up. At } 16-20 \text { months, the loss to follow-up for women enrolled in the study was } \\
51.4 \% \text { for the treatment group }(\mathrm{N}=18 / 57) \text { and } 6.3 \% \text { for the control group ( } N=8 / 57 \text { ). }\end{array}$ \\
\hline & $\begin{array}{l}\text { Randomisation method was stated. Strong possibility of selection bias ( } 22 \text { randomised to control } \\
\text { group, } 35 \text { to treatment group). }\end{array}$ \\
\hline & Data available are in an unsuitable form for analysis. \\
\hline
\end{tabular}

Characteristics of studies awaiting assessment [ordered by study ID]

Kersting 2011b

\begin{tabular}{ll}
\hline Methods & Randomised controlled trial \\
\hline Participants & $\begin{array}{l}83 \text { German speaking mothers who had lost a child during pregnancy through miscarriage, termina- } \\
\text { tion of pregnancy due to fetal anomaly, or stillbirth }\end{array}$ \\
\hline Interventions & 5-week internet-based cognitive behavioural therapy versus 5-week waiting condition \\
\hline Outcomes & $\begin{array}{l}\text { Relative to controls, participants in the treatment group showed significant improvements in post- } \\
\text { traumatic stress, grief, depression, and overall mental health, but not in anxiety or somatization. } \\
\text { Medium-to-large effect sizes were observed, and the improvement was maintained at 3-month fol- } \\
\text { low-up. } \\
\text { Stillbirth data were not separately reported. }\end{array}$ \\
\hline
\end{tabular}


Kersting 2011b (Continued)

Notes

Annette Kersting, the lead investigator of this trial, was contacted by the authors of this review on 11 April 2013, with the request to kindly provide data specific to women who had a stillbirth.

\section{A P P E N D I C E S}

\section{Appendix 1. Methods used to assess trials included in previous versions of this review}

Two review authors (Helen Chambers and Fung Yee Chan) independently selected the trials to be included in the orginal version of this review (Chambers 1998) with the reasons for exclusion of any apparently eligible trial clearly stated. Any disagreement was resolved by discussion. The same review authors assessed the methodological quality of the trials with details of randomisation, blinding and exclusions from the analyses recorded.

Review author (Vicki Flenady) subsequently assessed the quality of the identified trials as a part of the 2008 update of the review (Flenady 2008).

We attempted to contact trial authors for additional information to allow both assessment of methodological quality and to permit 'intention-to-treat' analysis of data. Dr Gillian Forrest and Professor Richard Lilford provided additional information about their published trials.

\section{Appendix 2. Methods for use in future updates}

\section{Selection of studies}

In future updates of this review, two review authors will independently assess for inclusion all the potential studies we identify as a result of the search strategy. We will resolve any disagreement through discussion or, if required, we will consult a third person.

\section{Data extraction and management}

We will design a form to extract data. For eligible studies, two review authors will extract the data using the agreed form. We will resolve discrepancies through discussion or, if required, we will consult a third review author. We will enter data into Review Manager software (RevMan 2012) and check for accuracy.

When information regarding any of the above is unclear, we will attempt to contact authors of the original reports to provide further details.

\section{Assessment of risk of bias in included studies}

Two review authors will independently assess risk of bias for each study using the criteria outlined in the Cochrane Handbook for Systematic Reviews of Interventions ( Higgins 2011 ). We will resolve any disagreement by discussion or by involving a third assessor.

\section{(1) Random sequence generation (checking for possible selection bias)}

We will describe for each included study the method used to generate the allocation sequence in sufficient detail to allow an assessment of whether it should produce comparable groups.

We will assess the method as:

- low risk of bias (any truly random process, e.g. random number table; computer random number generator);

- high risk of bias (any non-random process, e.g. odd or even date of birth; hospital or clinic record number);

- unclear risk of bias.

\section{(2) Allocation concealment (checking for possible selection bias)}

We will describe for each included study the method used to conceal allocation to interventions prior to assignment and will assess whether intervention allocation could have been foreseen in advance of, or during recruitment, or changed after assignment.

We will assess the methods as:

- low risk of bias (e.g. telephone or central randomisation; consecutively numbered sealed opaque envelopes);

- high risk of bias (open random allocation; unsealed or non-opaque envelopes, alternation; date of birth);

- unclear risk of bias. 


\section{(3.1) Blinding of participants and personnel (checking for possible performance bias)}

We will describe for each included study the methods used, if any, to blind study participants and personnel from knowledge of which intervention a participant received. We will consider that studies are at low risk of bias if they were blinded, or if we judge that the lack of blinding would be unlikely to affect results. We will assess blinding separately for different outcomes or classes of outcomes.

We will assess the methods as:

- low, high or unclear risk of bias for participants;

- low, high or unclear risk of bias for personnel.

\section{(3.2) Blinding of outcome assessment (checking for possible detection bias)}

We will describe for each included study the methods used, if any, to blind outcome assessors from knowledge of which intervention a participant received. We will assess blinding separately for different outcomes or classes of outcomes.

We will assess methods used to blind outcome assessment as:

- low, high or unclear risk of bias.

\section{(4) Incomplete outcome data (checking for possible attrition bias due to the amount, nature and handling of incomplete outcome data)}

We will describe for each included study, and for each outcome or class of outcomes, the completeness of data including attrition and exclusions from the analysis. We will state whether attrition and exclusions were reported and the numbers included in the analysis at each stage (compared with the total randomised participants), reasons for attrition or exclusion where reported, and whether missing data were balanced across groups or were related to outcomes. Where sufficient information is reported, or can be supplied by the trial authors, we will re-include missing data in the analyses which we undertake.

We will assess methods as:

- low risk of bias (e.g. no missing outcome data; missing outcome data balanced across groups);

- high risk of bias (e.g. high attrition (greater than 20\%) or reasons for missing data imbalanced across groups; 'as treated' analysis done with substantial departure of intervention received from that assigned at randomisation);

- unclear risk of bias.

\section{(5) Selective reporting (checking for reporting bias)}

We will describe for each included study how we investigated the possibility of selective outcome reporting bias and what we found.

We will assess the methods as:

- low risk of bias (where it is clear that all of the study's pre-specified outcomes and all expected outcomes of interest to the review have been reported);

- high risk of bias (where not all the study's pre-specified outcomes have been reported; one or more reported primary outcomes were not pre-specified; outcomes of interest are reported incompletely and so cannot be used; study fails to include results of a key outcome that would have been expected to have been reported);

- unclear risk of bias.

\section{(6) Other bias (checking for bias due to problems not covered by (1) to (5) above)}

We will describe for each included study any important concerns we have about other possible sources of bias.

We will assess whether each study was free of other problems that could put it at risk of bias:

- low risk of other bias;

- high risk of other bias;

- unclear whether there is risk of other bias.

\section{(7) Overall risk of bias}

We will make explicit judgements about whether studies are at high risk of bias, according to the criteria given in the Cochrane Handbook (Higgins 2011). With reference to (1) to (6) above, we will assess the likely magnitude and direction of the bias and whether we consider it is likely to impact on the findings. We will explore the impact of the level of bias through undertaking sensitivity analyses - see 'Sensitivity analysis'. 


\section{Measures of treatment effect}

\section{Dichotomous data}

For dichotomous data, we will present results as summary risk ratio with $95 \%$ confidence intervals.

\section{Continuous data}

For continuous data, we will use the mean difference if outcomes are measured in the same way between trials. We will use the standardised mean difference to combine trials that measure the same outcome, but use different methods.

\section{Unit of analysis issues}

\section{Cluster-randomised trials}

We will include cluster-randomised trials in the analyses along with individually-randomised trials. We will adjust their sample sizes using the methods described in the Cochrane Handbook using an estimate of the intracluster correlation co-efficient (ICC) derived from the trial (if possible), from a similar trial or from a study of a similar population. If we use ICCs from other sources, we will report this and conduct sensitivity analyses to investigate the effect of variation in the ICC. If we identify both cluster-randomised trials and individually-randomised trials, we plan to synthesise the relevant information. We will consider it reasonable to combine the results from both if there is little heterogeneity between the study designs and the interaction between the effect of intervention and the choice of randomisation unit is considered to be unlikely.

We will also acknowledge heterogeneity in the randomisation unit and perform a [sensitivity OR subgroup] analysis to investigate the effects of the randomisation unit.

\section{Dealing with missing data}

For included studies, we will note levels of attrition. We will explore the impact of including studies with high levels of missing data in the overall assessment of treatment effect by using sensitivity analysis.

For all outcomes, we will carry out analyses, as far as possible, on an intention-to-treat basis, i.e. we will attempt to include all participants randomised to each group in the analyses, and all participants will be analysed in the group to which they were allocated, regardless of whether or not they received the allocated intervention. The denominator for each outcome in each trial will be the number randomised minus any participants whose outcomes are known to be missing.

\section{Assessment of heterogeneity}

We will assess statistical heterogeneity in each meta-analysis using the $\mathrm{T}^{2}, \mathrm{I}^{2}$ and $\mathrm{Chi}^{2}$ statistics. We will regard heterogeneity as substantial if an $\mathrm{I}^{2}$ is greater than $30 \%$ and either a $\mathrm{T}^{2}$ is greater than zero, or there is a low $\mathrm{P}$ value (less than 0.10 ) in the Chi ${ }^{2}$ test for heterogeneity.

\section{Assessment of reporting biases}

If there are 10 or more studies in the meta-analysis, we will investigate reporting biases (such as publication bias) using funnel plots. We will assess funnel plot asymmetry visually. If asymmetry is suggested by a visual assessment, we will perform exploratory analyses to investigate it.

\section{Data synthesis}

We will carry out statistical analysis using the Review Manager software (RevMan 2012). We will use fixed-effect meta-analysis for combining data where it is reasonable to assume that studies are estimating the same underlying treatment effect: i.e. where trials are examining the same intervention, and the trials' populations and methods are judged sufficiently similar. If there is clinical heterogeneity sufficient to expect that the underlying treatment effects differ between trials, or if substantial statistical heterogeneity is detected, we will use randomeffects meta-analysis to produce an overall summary if an average treatment effect across trials is considered clinically meaningful. The random-effects summary will be treated as the average of the range of possible treatment effects and we will discuss the clinical implications of treatment effects differing between trials. If the average treatment effect is not clinically meaningful, we will not combine trials.

If we use random-effects analyses, the results will be presented as the average treatment effect with $95 \%$ confidence intervals, and the estimates of $\mathrm{T}^{2}$ and $\mathrm{I}^{2}$.

\section{Subgroup analysis and investigation of heterogeneity}

If we identify substantial heterogeneity, we will investigate it using subgroup analyses and sensitivity analyses. We will consider whether an overall summary is meaningful, and if it is, use random-effects analysis to produce it.

We plan to carry out the following subgroup analyses. 
1. Type of intervention: person delivering the intervention: clinician (midwife, obstetrician); professionals specifically trained in bereavement counselling; qualified psychologist/psychotherapist, other professionals (e.g. social workers, pastoral care workers), or other (e.g. bereaved parents).

2. Mode of delivery and intensity of the intervention: e.g. face-to-face, telephone or internet-based interventions, and the duration of time that specific support was provided (i.e. number of consultations).

3. High-risk population: interventions provided for parents or families, or both who are considered to be at increased risk, namely: 1) termination of pregnancy for fetal anomalies (TOP), 2) parents with previous mental illness, 3) complicated grief.

We will carry out subgroup analysis for primary outcomes only.

We will assess subgroup differences by interaction tests available within RevMan (RevMan 2012). We will report the results of subgroup analyses quoting the $\mathrm{X} 2$ statistic and $\mathrm{P}$ value, and the interaction test $\mathrm{I}^{2}$ value.

\section{Sensitivity analysis}

We will carry out sensitivity analysis: if we include trials at high risk of bias, we will temporarily remove them from the analysis, to examine the impact of excluding these trials; if we include cluster-randomised trials, we will examine the effect of varying the ICC.

\section{FEE D B A C K}

\section{Lang, September 2005}

\section{Summary}

The authors are to be commended for taking on the important, and often neglected, issue of providing support to bereaved families following perinatal loss.

None of the published studies met the quality criteria for inclusion in the review, and data on this topic are described as 'sparse' and 'variable'. In their discussion, the authors appropriately identify the limitations of their study, but then go on to state that the lack of trials was further complicated by "the evolution over 15 years of so called 'standard care' after perinatal death: the provision of an empathic caring environment, which was regarded in the earlier trials as part of the intervention, is now standard care in most centres". The basis for this conclusion is, however, questionable, and there is evidence to the contrary. Indeed, among health professionals there continues to be a sense of discomfort with the subject matter that frequently spills over into the care provided, which is often inadequate and can actually be detrimental.

Conclusions emanating from reviews where no quality studies are included must be carefully considered, and should be well-substantiated by other evidence. Ill-informed conclusions cited in The Cochrane Library can have an important impact on practitioners, researchers and funders.

(Summary of comments from Ariella Lang, September 2005)

\section{Reply}

We thank Ariella Lang for her comments and hope that our reply adequately addresses the concerns raised regarding our comments in the discussion of the review on the quality of current practice for parents after a perinatal death.

We agree that care for parents around the time of a perinatal death often falls short. We also agree that a sense of discomfort by healthcare professionals when dealing with a perinatal death may have negative effects on the quality of care and outcomes for parents. To better reflect this, the issue of care around the time of death is now discussed with appropriate references in the background, and the sentences about evolution of care have been removed from the background and discussion. Also, the list of interventions included in the review has been expanded to include support and education for professionals on perinatal bereavement. However, for this update we were not able to identify any randomised trials addressing this intervention.

The conclusions of the review clearly highlight the current lack of evidence to guide care and the need for well-designed trials to determine the appropriate support interventions for parents following a perinatal death. As is discussed in the conclusion, this lack of clearly defined and tested interventions may affect the confidence of practitioners, as well as funding opportunities, which may further contribute to the inadequate care currently provided to families who experience perinatal loss.

(Summary of reply by Vicki Flenady and Trish Wilson, May 2007)

\section{Contributors}

Feedback: Ariella Lang

Response: Vicki Flenady, Trish Wilson 


\section{WHAT'S NEW}

\begin{tabular}{lll}
\hline Date & Event & Description \\
\hline 15 March 2013 & $\begin{array}{l}\text { New citation required but conclusions } \\
\text { have not changed }\end{array}$ & $\begin{array}{l}\text { No new trials included. One new trial currently awaiting classifi- } \\
\text { cation (Kersting 2011b). }\end{array}$ \\
\hline 28 January 2013 & New search has been performed & Search updated. Methods updated. \\
\hline
\end{tabular}

\section{H I S T O R Y}

Protocol first published: Issue 3, 1997

Review first published: Issue 2, 1998

\begin{tabular}{lll}
\hline Date & Event & Description \\
\hline 23 November 2011 & New search has been performed & $\begin{array}{l}\text { Search updated and no new trials identified. Plain language } \\
\text { summary added. Background modified. }\end{array}$ \\
\hline 11 November 2010 & New search has been performed & List of contributing authors updated \\
\hline 29 January 2009 & Amended & Author's contact details edited. \\
\hline 11 February 2008 & Amended & Converted to new review format. \\
\hline 6 November 2007 & $\begin{array}{l}\text { New citation required and conclusions } \\
\text { have changed }\end{array}$ & Substantive amendment \\
\hline
\end{tabular}

\section{CONTRIBUTIONSOFAUTHORS}

For this update, Laura Koopmans and Trish Wilson revised the background and discussion of the previous version of this review, in collaboration with Vicki Flenady and Joanne Cacciatore.

\section{DECLARATIONSOF INTEREST}

None known.

\section{SOURCES OF SUPPORT}

\section{Internal sources}

- Mater Medical Research Institute and the Mater Mothers' Hospitals, Mater Health Services, Brisbane, Australia.

\section{External sources}

- NIHR NHS Cochrane Collaboration Programme grant scheme award for NHS-prioritised centrally-managed, pregnancy and childbirth systematic reviews: CPGS 10/4001/02, UK.

\section{N DEX TERMS}

\section{Medical Subject Headings (MeSH)}

*Bereavement; *Counseling; *Death; *Nuclear Family; *Social Support; Life Change Events

\section{MeSH check words}

Humans; Infant, Newborn 